\title{
Appropriate Use of Synonyms in English and Uzbek
}

\section{Malika Abdulkhaeva ${ }^{1}$ Maftuna Suyunova $^{2}$ Lobarkhon Artykova $^{3}$ Sardora Abrarova ${ }^{4}$}

\author{
${ }^{1}$ Senior Lecturer Interfaculty department of the English language, National University of \\ Uzbekistan named after Mirzo Ulugbek. \\ ${ }^{2}$ Lecturer Interfaculty department of the English language, National University of \\ Uzbekistan named after Mirzo Ulugbek. \\ ${ }^{3}$ Lecturer Interfaculty department of the English language, National University of \\ Uzbekistan named after Mirzo Ulugbek \\ ${ }^{4}$ Lecturer Interfaculty department of the English language, National University of \\ Uzbekistan named after Mirzo Ulugbek.
}

Email: ${ }^{1}$ stalker.malika@gmail.com, ${ }^{2}$ suyunova93@bk.ru, ${ }^{3}$ lobarkhon55@gmail.com,

${ }^{4}$ sardoraabrarova@gmail.com

\begin{abstract}
:
This article sets a number of tasks for linguists and teachers in the theoretical and practical study of synonyms in modern English.This requires some measures to facilitate the process of teaching English and establishing conversational communication. To develop students' understanding of the use of synonyms in English.
\end{abstract}

Keywords: synonyms, human communication, existence, human society human life experiences,lexicon,

Article Received: 16th October, 2020; Article Revised: 30th December, 2020; Article Accepted: 08th January, 2021

\section{Introduction}

Language is the most important means of human communication. In this connection, speech and speech play the most important role in the interaction and thinking of people. A word expresses an idea in a sentence, and a sentence is made up of words, the material of which is the word.Thus, the word is the basis of grammatical construction, the most basic unit of language in both lexicon and grammar. A word is a sound expression of the concept of an object or event in an objective being. This concept is the reflection of an object or event in the mind. The word reflects various aspects of existence, human society human life experiences. The study of the word has come a long way in its development.It is necessary to carefully study the scientific heritage added to science through their activities.

The word helps to know the history, so that it does not repeat the situations that are likely to be accepted by different theories and opinions put forward by different scholars

The science of language has been recognized in Europe since the early 19th century as an independent science, among other disciplines. However, the interest of scientists in the word structure began much earlier.In ancient times, word problems were often combined with other problems, such as philosophy, music, the correct reading of old memoirs, and even the natural sciences. The system of sound exchange, that is, internal inflection, used in the construction of words or word forms, was described by Indian scholars as 
early as $\mathrm{AD}$. Ancient Indian grammarians considered the word to be the basic unit of speech, as it did not have the ability to express an idea, and the word did not exist outside the sentence. The ancient Indian linguists did a great deal of work in the field of phonetics as well. This is because Indian scientists have noticed that during the development of languages, changes can occur not only in the meanings of words, but also in the sound system.Dictionaries were compiled in ancient India at the beginning of the first millennium $\mathrm{BC}$. Socrates says this about the word; "Words must also correspond to what the mutual consciousness means, which means that they have certain accuracy from the very beginning. Not everyone can create words. Only someone who knows how to create words and the nature of things can do that.

\section{Main part}

Synonymy is one of the traditional categories, and in theory it is almost unexplored. Usually synonyms are generally identified through examples that are considered typical, approximate. O.S. Akhmanova expresses her opinion on this issue as follows. A common concept in linguistics is synonyms, that is, words that have different pronunciations, the same meaning, or the same meaning. AB Sharipov clarifies this definition, "Words that have the same meaning, differ in sound structure are not synonyms such compatibility does not exist in languages." Thus, synonyms are words that differ in sound structure and combine one or another difference in their similar meanings.

R. A. Budagov gives an opinion close to this definition: "Synonyms are words that are semantically close, but have the same meaning in different pronunciations. Although all synonyms are different words and have the same meaning, they always have the same meaning. Synonyms testify to the fact that people convey the same meaning through different words."
Sometimes the definitions of synonyms are determined by their classification. One of such definitions is that of K.A. Levkovskaya."'Synonyms are words (ideographic) synonyms that are compatible in terms of nominative content differ from each other in terms of usage and various additional meanings". In addition, they differ from each other by their stylistic usage (stylistic synonyms) or their area of distribution, on the one hand, common synonyms, on the other hand.

Defines and applies synonyms by grouping. It is reflected in the following words of S. Ulman: "Only words can be defined as synonyms that can replace each other in any text without any changes in the meaning of the effect." Based on this definition, S. Ulman identified pure synonyms, that is, words that do not exist in a periodic sense and replace each other in terms of logical and emotional properties.

False synonyms are divided into the following parts:

a) We analyze synonyms that exist from a periodic point of view and are interchangeable only in some texts. Example: lamp-jump, hilper-aider, assistance.

The two sleepy helpers put the wrong harness on the wrong horses.

She couldn't find for herself neither an aider nor a counselor she was alone with her troubles and difficulties. (Dickens) He was presented to a clerk in the wordens office and his name and crime entered in the book-himself assigned to two assistents who saw to: if that he was given a prison both and hair cut (Drieser).

In our first sentence, it is used in the sense of helpers, and the original meaning of the word helpers is a person who helps in a certain work. In the second sentence, the word aider and the word an anider in the sense of a helper, a helper, is a person who helps with respect in work, in some ways.In our third sentence, the word "assistant" means an assistant. When we analyze the words helpers and an anider in 
our first and second sentences, the constant meaning of helpers is used in a particular case, and the word an anider comes in the sense of helping with respect, but stylistically interchangeable. It cannot be replaced.

b) We analyze synonyms that exist in a periodic context and are interchangeable not in terms of emotion but in terms of meaning. For example:liberty-freedom, hide-concial.

$>$ He approach of liberty makes even an old man brave. Education is a better safeguard of liberty then a stamina army. (Proverbs).

$>$ The agreement which provides that U. S. Government must at all times ensuresfreedom of access to the United Nations headquarters. (Daily worker 1960).

$>\mathrm{He}$ has a secret should not only hide it, but hide that has it to hide.

$>$ Clyde had managed to conceal his realations. (Bennett).

Here the words liberty and freedom are exchanged very quickly. The word "freedom" means freedom, freedom, and when we speak of a state or an individual, it means to be free. Liberty in Uzbek means to be free, to achieve freedom, and to do, to say, to have freedom of action.

A freer understanding of synonymy can be found in the following passage from Rothen's Thesaurus. For example, consider the word "nice". We can see different synonyms in the word "nice" in different meanings.

Uzbek linguist Azim Hoshiyev describes synonyms as follows: - "The pronunciation of synonyms has the same unifying meaning, a number of additional meanings, such as subtlety, emotional order, usage are words that differ in their properties."

B. A. Ilish says that when we semantically classify words, they fall into two categories, and these are synonyms and antonyms. Synonyms are different words, words that have the same or similar meanings. English is a language rich in synonyms.

For example: want, wish, desire, crove, covet are synonyms such as want, feel the need. These synonymous words differ from each other in the effectiveness of the desire for character.

a) They wonted only truth (Galsworthy)."The man of properly".

b) They just want the truth.

c) $\mathrm{He}$ wished to be home (J. London)

d) I wish I were 9 yipsy (A. J. Gromin)

e) He finally receieed his position he desired. (G. Greene).

f) $\mathrm{He}$ croved fresh fruit (O. Henry)

g) He coveted place and wordly wealth. (A. Christie)

The synonyms want and wish in the first and second sentences have the same meaning and can be stylistically interchangeable. In our third sentence, the word wish means events that do not occur in the construction of a command, a wish. There is no chance that it will happen. In the fourth sentence, desire is close to the meaning of desire, but a strong goaloriented desire, which contains a definite desire. In our first speech, the word croved comes in the sense of a very strong desire, which gives rise to unsatisfactory strengths.

\section{History of the origin of synonyms}

It is very important to distinguish between synchronous and diachronic aspects, it is impossible to imagine, but it is difficult to understand both aspects independently and without each other. Therefore, we will consider the historical analysis of synonyms, the historical approach to synonyms in modern English, the origin of synonyms and the reasons for their use in English.

Words from the French language can be found in more official and various 
literatures. For example, take the words begin-commence and wood-forest.

Sometimes French words are used in modern speech. And Anglo-Saxon words can be found in poetic and archaic literature. A. Imish gives an example deen and consider or language units.

O. Jesperson and other scholars say that the richness of English words is synonymous with the word during the wars between the British, Saxons, Danes and Normans, or during the conquest of the British Isles. However, Arnold believes that these words affected each other.

Synonyms have their own character in each language. Its peculiarities in English are simple and local words are stylistically neutral and literary words derived from French words and their origin can be seen in Latin words.

We can see such stylistic conclusions as follows.

Native English words borrowed from.

\begin{tabular}{|lr|}
\hline Word & from French \\
Latin & stomach \\
To ask & finish \\
to interrogate & \\
Belly & \\
abdomen & to assemble \\
To end & \\
complete & guidance \\
To gather & \\
collect & to guestion \\
Teaching & \\
instruction & \\
& \\
\hline
\end{tabular}

The source of English synonyms came from the words kellenik and roman. For example:periphery, circumstence, hypothesis, supposition, sympathy, compassion, synthesis, composition.

In the 13th century, the word soil came from English to mean strip of the land. In Old English, forests and vegetation are synonymous with corpe, land, folde.

At the heart of these words are other meanings. If two words now have the same meaning in use and application, one of them will fall out of the competition, the meaning of the word folde is the same as the first word in the use of the letters "corpe" in the same medium. The meaning of the word "folde" is not unusual. Many other words are "archaic" or "abstract" in dictionaries and fall into such competition. Others have very little or no meaning. This process is called synonymic differentiation, which the great linguist $\mathrm{M}$. Breal points out as a real rule in language developmentas you can see.

Synonyms affect each other semantically in two opposite ways. The first dissimilation (dissimilation), the second process is called assimilation. The process of assimilation of synonyms implies parallel development. For example, in Middle English we can get the meaning of the English word swifty and the word immediately. This rule was discovered and explained by the English linguist G. Sterk. Dialects played an important role in the growth of English synonyms, and many words came from dialects. In the last century, dialects have taken a prominent place in the American English version. For example: Yimmicktrick, subscription; long distance, trunk call; radio.

These methods are also evolving in synonyms. Many synonymous groups continue to be in a separate relationship as an element. We explain this situation with examples.

- To choose: to pick out, to entertocome in

- To abandon: to give up, to lift-to pick up.

- To continue: to go on, to post pone-toput off

- To quarrel: to fall out, to return-to bring back

- By the way, to has quite given up the idea of doing those animal (300 b) cartoons. (Maugham. The Moon of Sixpence)

- My brother has quarreled with me and give up me (dickens).

- I resolved to give up my from sell my stock and remove (helston). 
- Good fortune did not abahdon him (shokespeare).

Sh.Amasova emphasizes the continuity of the connection between the structure of the phrase and the semantic effect on the behavior of the phrases. He again draws attention to one thing, noting that in phraseological combinations the meaning varies completely. In this work we can cite phraseological combinations to give a lift, to give somebody wite a furn.

\section{Information about synonyms in English}

Synonyms are divided into ideographic (spiritual) and stylistic types.

Ideographic synonyms have the same meaning and belong to the same neutral stylistic types.

For example: power, force-kuch, energyquvvat words.

She began to look at pictures with great energy. (Jhackeray).

They held him firmly but used no force (pone).

He power of the waves battered down the wall (longthon).

In the examples given, we can use synonyms instead of each other. Stylistic synonyms are sometimes called emotionally expressive. We compare the words in the synonymous series belonging to different stylistic types as follows.

For example: bad, ill, ivel, wicked-means bad, sick.

He bad news had an evil consequence. (Gray)

Ill news goes fast (proverb).

A bad character is the consequence of immoral conduct, but a wicked character is one who has been guilty of some known and flagrant vice (I. Swift).

In the course of this analysis, you may come across the stylistic synonym ill - ill ill or evil - evil. You can see the stylistically correct use of the expressive coloring of the words in these sentences.

Excellent - ideographicsynonyms are always stylistically the same, stylistic synonyms are different when compared to stunning-topping stylistic synonyms from another point of view. According to this view, the ideographic pair is excellentsplendid-stunning-toping, which are stylistically similar. The first is stylistically neutral excellent splendid, the second is stylistically tuned, if we place these words in one of the synonyms, excellent-splendid-stunning-find then these synonyms become stylistic synonyms.

Total synonymy -this group of synonyms can replace each other in any context without change or emotional meaning. We can deduce the knowledge related to these synonyms from specific technical terms. For example: linguistic terms noun-noun and substantive-noun, functional affix -adverb, flection-adverb, etc. have the same meaning.

In short, the full expression of the originality of the events, the concrete expression of the attitude to it, and the choice of words with a similar requirement, adapts to a particular type of style.

\section{Analysis of the translation of English synonyms into Uzbek}

The task of translation is not only to convey the meaning of words and phrases, but also to reveal the most subtle and elegant features of the author's style, such as the semantic phenomenon hidden behind the sequence of words and phrases. The most important feature of the work of art was its novelty in the choice of words and word combinations. It consists of the correct representation of the image, knowing the artistic function of each sound, speech and comma. It is not important for a translator who does not understand or pay attention to such small and delicate language features to translate correctly.

For example: passed away in the world of death, stretched his legs, went to sleep forever, died, died, died, died, performed slavery, handed over the deposit. Many of these synonyms and phrases are good to use in their proper place, but if used incorrectly, a serious mistake can occur. 
For example:Instead of saying "he died" or "he went to Asfalasofin" instead of "he passed away", he did not say "he died".

Every translator has his own style, as L. I. Temafiv said, as many writers as there are styles. There will never be writers of the same style. Every artist has a different worldview, perception of events people's attitude to natural phenomena. This is reflected in their works.

In these cases, the words objects, reasons, goals, purpose, desire are semantically synonymous. However, the words desire and reason can never be synonymous, because desire means desire, reason-cause means purpose, but in the context these words are used equally. In general, it should be noted about the translation of the novel "Anna Korenina", which incorrectly translated some words, sentences and phrases that violated some national features of the original, did not find synonyms for them, stylistically incorrect sentences created.

Let's look at some examples of what it means when we translate English synonyms into Uzbek and what their function is in both languages.

For example: Expect, hope a wait synonyms vary in meaning. Of these, expectation and hope can be used interchangeably.

These synonyms are used when you expect something to happen.Expect means to think, dream and wait for someone to come. Hope is used in the sense of believing that something will happen. Hope is associated with pleasant desires. Expect and hope to enter into different syntactic relationships. The verb Expect serves to connect the infinitive construction of the complement in the following sentences and connects the possessive and infinitive construction when the passive pronoun is used.

Anna opens the door and hopes orders (show)

I expect it's a book by York harding. ( $G$. Greene. "P. x. Y")
Sabina was expected to be deferential to woman

In both sentences it came as a predicate, and when translated into Uzbek it came as a cut.

\section{Conclusion}

Summing up the research on the analysis of the translation of English synonyms into Uzbek, synonymous words are not just a luxury, but a real richness of the language. Synonyms are one of the most meaningful forms of the word, with a number of features, such as the pronunciation, spelling, additional semantic subtlety, the use of emotional meaning, which have the same unifying meaning are words that are constantly different.

When it comes to synonyms, we divide synonyms in linguistics mainly into ideographic and stylistic types.

Ideographic synonyms, for example: to understand-to realish, to expeet-to anticipate-to understand, to comprehend, to expect, to anticipate - have the same meaning and belong to the same neutral stylistic type.

Stylistic synonyms are sometimes called emotionally expressive. Stylistic synonyms have different meanings depending on their stylistic features. For example: to help - to aid - to assist means to help.

According to the above definitions, synonymy is mainly semantic in any case, the definition of synonyms is based on stylistic criteria, other criteria and pure semantic criteria.

Synonyms always give unexpected units or logical meanings, so synonymous repetition decorates the work stylistically. The ideographic synonym is used by the translator in the worst case to avoid the poor, colorless expression that occurs as a result of the repetition of language units.

Regardless of the fact that a series of synonyms consists of several words, one word in it is the main word that determines the nature of this synonymous series. This word is called dominant. The correct 
definition of the key word in this box plays an important role in defining the boundaries of the synonym series, as well as in revealing the specificity of each word in it. In a synonymous series, a word that has a wider range of meanings than the others is the key word. We can classify synonyms with syntactic and morphological and, of course, a lot of attention to meaning.

We can cite the words wet, moist, humid, damp and dank in the synonymous series of quality. The synonymous series in this category often comes as a cut and determiner in the sentence.

For example: His shirt was wet wish sweat. (M. Twain)

In this sentence it came as a wetpredicative function, and when translated into Uzbek it also came as a complex verb. In short, synonyms are words that differ in their nominative content, features of the content of use, and different additional meanings.

\section{References}

[1] Vilyuman V. G. "English synonymy". Moscow: 1980.

[2] Salakhova, E. Z., \& Shamsitdinova, M. G. (2020). ADVANCED PEDOGOGICAL TECHNOLOGIES IN EDUCATION IN THE 21-ST CENTURY. Theoretical \& Applied Science, (5), 743-746.

[3] Arnold V. "The stylistics of modern English". Moscow: 1980

[4] Shamsitdinova, M. G. (2020). INTERCULTURAL COMMUNICATION AND PROBLEMS OF TEACHING ENGLISH TO THE STUDENTSNONLINGUISTS. Theoretical \& Applied Science, (4), 1024-1026.

[5] Jesperson O. "growth and structure of the English language" L - 1930.

[6] Salakhova, E., Shamsitdinova, M., \& Shakhakimova, M. (2020). THE IMPACT OF INFORMATION TECHNOLOGIES ON DISTANCE
EDUCATION DURING PANDEMIC IN THE REPUBLIC OF UZBEKISTAN. PalArch's Journal of Archaeology Egypt/Egyptology, 17(6), 8962-8967.

[7] Grabb`s "English synonyms". Lond

[8] Shamsitdinova, M. (2020). IMPLEMENTATION OF IT AND ICT INTO EDUCATION: MULTIMEDIA TECHNOLOGIES IN CREATING AND USING ELECTRONIC BOOKS. Theoretical \& Applied Science, (11), 5-10.

[9] Galperin I. R. "Stylistics" - Moscow 1977.

[10] Gandelsman "English synonyms". Moscow 1965

[11] Y. I. Godlennik, e. V. Malishevskaya "English synonyms their meanings and usage". Moskva 1965.

[12] Baskakov, Sodiqov "Umumiy tilshunoslik". O'qituvchi

[13] Salakhova, E., Shamsitdinova, M., \& Shakhakimova, M. (2020). THE IMPACT OF INFORMATION TECHNOLOGIES ON DISTANCE EDUCATION DURING PANDEMIC IN THE REPUBLIC OF UZBEKISTAN. PalArch's Journal of Archaeology of Egypt/Egyptology, 17(6), 8962-8967.

[14] Ilish V. A. "The structure of modern English" M. 1965.

[15] Shamsitdinova, M. G. (2020). INTERCULTURAL

COMMUNICATION AND

PROBLEMS OF TEACHING

ENGLISH TO THE STUDENTSNONLINGUISTS. Theoretical \& Applied Science, (4), 1024-1026.

[16] Odilov, B. A., \& Karimov, N. R. (2020). ANALYSIS OF TARGETED RESEARCH IN 20-30 YEARS OF THE XX CENTURY.PalArch's Journal of Archaeology of Egypt/Egyptology, 17(6), 8887-8893.

[17] Shamsitdinova, M. (2018). Methodological and linguistic bases for intergrating the four 
skills. Review of law sciences, 2(4), 25.

[18] Rustamiy, S. A. (2019). Poetical art of Yusuf Balasagun. ISJ Theoretical \& Applied Science, 9(77), 256-259.

[19] Sayfullaev, N. Current Issues on Fine ARTS Education: Continuity and Prospects for Development. Religación, 4, 192194.

[20] Shamsitdinova, M. G. (2020). INTERCULTURAL COMMUNICATION

AND PROBLEMS OF TEACHING ENGLISH TO THE STUDENTSNONLINGUISTS. Theoretical \& Applied Science, (4), 1024-1026.

[21] Sodirjonov, M. M. (2020). On the coverage of ethnic processes in the information space. Asian Journal of Multidimensional Research (AJMR), 9(6), 165-171.

[22] Mahamadaminovich, S. M. (2020). THE ESSENCE OF SOCIAL CAPITAL CONSEQENCES AND THEIR INFLUENCES TO THE MODERN SOCIETY. Вестник науки и образования, (2-2 (80)).

[23] Sodirjonov, M. M. (2020). Some Thoughts On The Evolution Of Approaches To The Concept Of Human Capital. The American Journal of Social Science and Education Innovations, 2(08), 144150.

[24] Doniyorov, A., Kariev, A., Aminov, H., \& Karimov, N. (2021). The Level of Study of the Religious Image of Mavarounnahr in the IX-XII Centuries. Journal of Contemporary Issues in Business and Government Vol, 27(1).

[25] Hormes, J. M., \& Rozin, P. (2010). Does "craving" carve nature at the joints? Absence of a synonym for craving in many languages. Addictive behaviors, 35(5), 459-463.

[26] Sobirov, Q. S. (2020). USE OF SYNONYMS IN SPEECH OF CHARACTERS OF UZBEK
DRAMA WORKS. Theoretical \& Applied Science, (2), 634-638.

$\begin{array}{lr}\text { Berdiev, S. } & (2020) . \\ \text { PHRASEOLOGISM: } & \text { ESSENCE, } \\ \text { CLASSIFICATION, } & \text { THE } \\ \text { METHODS } & \text { OF } \\ \text { TRANSLATION. Mental } & \end{array}$

Enlightenment Scientific-

Methodological Journal,2020(1), 159-169.

[28] Doniyorov, A., Kariev, A., Aminov, H., \& Karimov, N. (2021). The Level of Study of the Religious Image of Mavarounnahr in the IX-XII Centuries. Journal of Contemporary Issues in Business and Government Vol, 27(1). 